\title{
Electrochemical Corrosion Behaviour of Cerium Chemical Conversion Coatings on 304 Stainless Steel in Alkaline Solutions Containing Chloride Ions
}

\author{
Sensen Xin ${ }^{1,2}$, Ronghai Xu ${ }^{1}$, Haitao Yan ${ }^{2}$, Peng Shen ${ }^{2}$,Moucheng Li $i^{1, *}$ \\ ${ }^{1}$ Institute of Materials, School of Materials Science and Engineering, Shanghai University, 149 \\ Yanchang Road, Shanghai 200072, China \\ ${ }^{2}$ Zhenshi Group Eastern Special Steel Co., LTD., Jiaxing 314005, Zhejiang Province, China \\ *E-mail: mouchengli@ shu.edu.cn
}

doi: $10.20964 / 2019.12 .84$

Received: 14 September 2019 / Accepted: 15 October 2019 / Published: 29 October 2019

\begin{abstract}
A chemical conversion coating was successfully prepared on the surface of 304 stainless steel (SS). The morphology and chemical composition of the obtained coating were analysed by scanning electron microscopy (SEM) and energy dispersive spectrometry (EDS). The electrochemical corrosion behaviour was investigated in $3.5 \mathrm{wt} \% \mathrm{NaCl}$ with different $\mathrm{pH}$ values. The results show that the chemical conversion coating is quite stable in alkaline solutions containing chloride ions. The coated 304 SS shows much higher corrosion potential and pitting potential in comparison with the uncoated 304 SS. It is suggested that the chemical conversion coating can noticeably improve the pitting corrosion resistance of 304 SS. In addition, the cerium chemical conversion coating shows good pitting resistance in an alkaline solution with increasing $\mathrm{pH}$ values.
\end{abstract}

Keywords: Stainless steel; Chemical conversion; Coating; Corrosion; Rare earth;

\section{FULL TEXT}

(C) 2019 The Authors. Published by ESG (www.electrochemsci.org). This article is an open access article distributed under the terms and conditions of the Creative Commons Attribution license (http://creativecommons.org/licenses/by/4.0/). 